\title{
Prevalence of Gastrointestinal parasites of Poultry in and around Banglore
}

\author{
G.C. Puttalakshmamma, Ananda, K. J., Prathiush, P. R. Mamatha, G. S. and Suguna Rao \\ Centre of Advanced Studies, \\ Department of Veterinary Parasitology, Veterinary College, \\ Karnataka Veterinary, Animal and Fisheries Sciences University, Hebbal, Bangalore-24, India
}

\begin{abstract}
In the present study 100 desi and 100 farm birds were screened for the presence of gastrointestinal parasites. Among 100 desi birds screened, 71 were found positive of gastrointestinal parasites by gross examination of gastrointestinal tract. Out of 71 positive desi birds, $35(52.2 \%)$ were found positive for cestodes, 23 (34.3\%) harbour nematodes and remaining 13 (18.3\%) had mixed infection. However there were no adult helminthes and helminthes ova was observed in farm birds except the gut contents showed Eimerian oocysts in 10 birds out of 100 birds by microscopic examination.
\end{abstract}

Keywords: Gastrointestinal parasites, Bird, Eimerian oocysts, cestode, nematode, mixed infection.

\section{Introduction}

Poultry farming has tremendously developed in recent years and has become one of the most intensive forms of animal husbandry activities. Though the impact of parasitic diseases in farm birds reared on cage systems have diminished due to modernization in poultry farming and biosecurity measures, but farm birds maintained on deep litter system and backyard free ranging birds still remain susceptible to parasitic infection via litter droppings and scavenging habits. The common internal parasitic infections occur in poultry include cestodes, nematodes and coccidia. These worm infections may cause considerable damage and great economic loss to the poultry industry due to malnutrition, decreased feed conversion ratio, weight loss, lowered egg production and death in young birds.

Improved poultry management practices are responsible for the reduction in incidence of parasitic infections. However due to abundance of intermediate host they visit the poultry pens for carrying food material or for feeding like in beetles, ants, and hoseflies which abundant on poultry litter droppings are responsible for transmission of various helminthes.

\section{Materials and Methods}

A total of 100 intact whole intestines of both desi and farm birds were collected from local poultry stalls located in and around Bangalore. The intestines were dissected longitudinally and screened for the presence of helminthes parasites. The adult parasites recovered from the intenstine were preserved in $10 \%$ formalin for identification.
Intestinal contents were also examined by sedimentation and flotation methods as per the procedure of Bowman and Lynn (1995) for the presence of helminthes ova/coccidian oocysts. The samples found positive for oocysts were kept for sporulation at room temperarure by using $2.5 \%$ potassium dichromate solution. The sporulation of oocysts was observed by 12 hours interval. The oocysts were identified based on sporulation time, morphology and micrometry and OPG (oocyst per gram of feces) by McMasters method as per Bowman and Lynn (1995).

The scrapings from caeca were also collected and exmined for the presence of schizonts and merozoites after geimsa's staining. In addition pieces of caecum were collected in $10 \%$ Neutral Buffered Formalin for hostopathological studies (Luna, 1968).

\section{Results and Discussion}

In the present study 100 desi and 100 farm birds were screened for the presence of gastrointestinal parasites. Among 100 desi birds screened, 71 were found positive of gastrointestinal parasites by gross examination of gastrointestinal tract (Fig. 1). This in accordance with Raote et al., (1991) they found $71.10 \%$ positive for parasitic infection in desi fowls on intestinal examination in Akola region of Maharastra. Out of 71 positive desi birds, $35(52.2 \%)$ were found positive for cestodes, $23(34.3 \%)$ harbour nematodes and remaining 13 $(18.3 \%)$ had mixed infection. The similar observations were made by Nadakal et al., 1972 who reported highest prevalence rate of cestodes followed nematodes and trematodes in desi birds. 


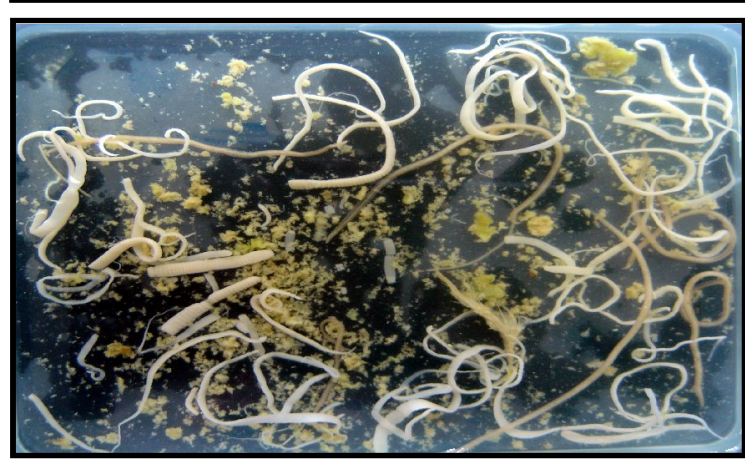

Fig.1. I ntestinal Contents showing Nematode and Cestode parasite

But in the present study none of the birds harbour trematode parasites, might be due to non accessibility of infected snails.

Of the 35 intestines positive for cestodes, 28 $(80 \%)$ were positive for Raillientina tetragona and 7 (20\%) had Raillietina echonobothrida (Fig. 2). Smilarly Hegde, et al., 1973 reported prevalence of Raillietina tetragona and R.echonobothrida as 77.1 and $57.8 \%$ in desi birds. Among 23 intestines which were positive for nematodes, 21 (91.4\%) had Ascaridia galli, one had Heterakis gallinarum (4.3\%) and other one had Subulura spp. (4.3\%) seen as single infection. Ascaridia galli had the highest prevalence rate followed by a Heterakis gallinarum and Subulura spp., respectively. Negesse et al., (1991) reported Subulura brumpti (40\%) followed by Ascaridia galli (34\%) and Heterakis gallinarum (24\%) in Ethiopia. The low prevalence of Heterakis gallinarum and Subulura spp. might be due to regional variation.

Thirteen desi birds showed mixed helminthic infections of Ascaridia galli, Rallietina tetragona and R.echinobothrida. Among mixed infection Ascaridia galli and Rallietina tetragona were recorded in 10 desi birds and all the three helminthes viz., Ascaridia galli, Rallietina tetragona and R.echinobothrida were observed in remaining 3 desi birds. However Raote et al., (1991) reported $50.97 \%$ of mixed infection in desi birds in Akola regions in Maharastra. The lowest prevalence rate of mixed infection in the present study might be due to regional variation.

The intestinal contents of 100 desi birds were also examined by sedimentation and flotation methods showed the ova of Ascaidia galli and strogyloides avium in only one bird by flotation method and no oocysts were observed in birds.

However there were no adult helminthes and helminthes ova was observed in farm birds except

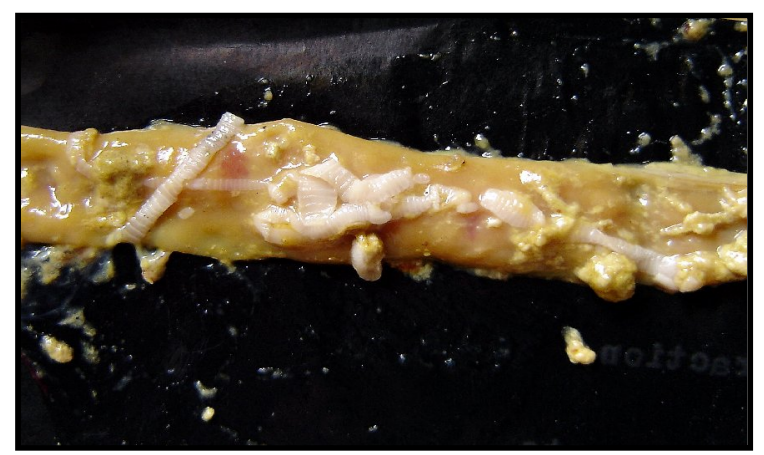

Fig.2. Tapeworm embeded on the intestinal mucosa

the gut contents showed Eimerian oocysts in 10 birds out of 100 birds by microscopic examination. In the present study two types of Eimerian oocysts were recorded and identified as E.tenella and E.necatrix based on the morphology and micrometry. The micrometry of these oocysts revealed $18.2 \mu \mathrm{m} \times 22.2$ $\mu \mathrm{m}$ for E.tenella oocysts and $13.8 \mu \mathrm{m} \times 15.5 \mu \mathrm{m}$ for E.necatrix oocysts, respectively. Morphologically the E.tenella oocysts was elongated where as E.necatrix was round in shape. The sporulation time of E.tenella and E.necatrix was found to be 18 and $24 \mathrm{hrs}$, respectively. Oocysts were counted by McMaster technique and they were in the range of $1,50,000$ to $1,75,000$ per gram of feces collected from intestines of farm birds. However the histopathological examination of caecal scrapings of farm birds infected with Eimerian oocysts revealed necrosis of villous epithelium, massive haemorrhages and infiltration of inflammatory cells in the lamina propria and submucosa. The schizonts, merozoites and oocysts were also observed in lamina propria.

\section{References}

1. Bowman, D. D. and Lynn, R.C., (1995): Georgis Parasitology for Veterinarians, 6th edn. W.B. Saunders company, Sydney.

2. Hemalatha, A. E., Abdul Rahman and Jagannath, M.S., (1987): Mysore J. Agri. Sci., 21: 338-341.

3. Hegde, K.S., Abdul Rehman, Rajasekariah, G.R., G.R., Ananth, M. and Bragitha Joseph. (1973): Mysore J. Agri. Sci., 7: 102-105.

4. Luna, A.G. (1968): Manual of Histological staining methods of the armed forces institute of Pathology. 3rd Edn. L.G. Mcgnow-Hill Book Co., New York, USA.

5. Nadakal, A.M., K.O. John, K. Muralidharan and Mohandas, A. (1972): Indian J. Anim. Health. 5-9.

6. Negesse, T. (1991): Indian J. poult. Sci., 26(2): 128-129.

7. Raote, Y.V., J oshi, M.V., Bhandarkar, A.G. and Bhawat, S.S. (1991): Indian J. poult. Sci., 26(2): 128-129.

Veterinary World · www. veterinaryworld.org · Vol.1, No. 7, July 2008 